Revista Brasileira de Cartografia

ISSN 1808-0936 | https://doi.org/10.14393/revbrascartogr

Sociedade Brasileira de Cartografia, Geodésia, Fotogrametria e Sensoriamento Remoto

\title{
Identificação dos Terrenos Sujeitos ao Parcelamento, Edificação ou Utilização Compulsória - PEUC com Uso de Geotecnologias Livres
}

\author{
Identification of Land Subject to Compulsory Subdivision, Building or Utilization of Land \\ Use - PEUC Using Free Geotechnologies
}

Tiago Umberto Pazolini ${ }^{1}$, Everton da Silva ${ }^{2}$ e Kaliu Teixeira ${ }^{3}$

1 Universidade Federal de Santa Catarina, Departamento de Geociências, Florianópolis, Brasil. tiago_pazolini@hotmail.com ORCID: https://orcid.org/7076-3983-9445-5073

2 Universidade Federal de Santa Catarina, Departamento de Geociências, Florianópolis, Brasil. everton.silva@ufsc.br ORCID: https://orcid.org/7515-4002-3541-3198

3 Universidade Federal de Santa Catarina, Departamento de Geociências, Florianópolis, Brasil. Kaliu12@gmail.com ORCID: https://orcid.org/5833-6766-0814-4078

Resumo: O Parcelamento, Edificação ou Utilização Compulsórios - PEUC é um instrumento jurídico e político previsto no artigo 182 da Constituição Federal de 1988, e regulamentado pela lei federal 10.257 de 2001, o Estatuto da Cidade. O PEUC visa o princípio da função social da propriedade urbana, estimulando que os terrenos não utilizados, subutilizados e não edificados cumpram com os parâmetros de uso e ocupação do solo exigidos pelo plano diretor. $\mathrm{O}$ presente estudo visa demonstrar procedimentos baseados em geotecnologias livres e gratuitas para a identificação de terrenos sujeitos ao PEUC. A área utilizada para demonstração localiza-se no bairro Campeche em Florianópolis, Santa Catarina. Com o emprego do método proposto, a execução dos procedimentos foi completamente realizada com o programa livre QGIS, e foram identificados 21 terrenos não edificados e 57 terrenos subutilizados.

Palavras-chave: Política Urbana. Estatuto da Cidade. Função social da propriedade. Geotecnologia.

\begin{abstract}
The Compulsory Subdivision, Building or Utilization of Land - CSBU, is a legal and political instrument provided for in Article 182 of the Federal Constitution of 1988, and regulated by Federal Law 10,257 of 2001, or City Statute. PEUC aims at or the principle of the social function of urban property by encouraging that unused, underutilized and unedited land comply with the land use and occupation parameters required by the master plan. This study aims to demonstrate free and free geotechnology-based procedures for identifying lands subject to PEUC. An area used for demonstration in the Campeche neighborhood in Florianópolis, Santa Catarina. Using a proposed methodology, it was possible to perform all procedures using the QGIS program, where it was possible to identify 21 unedited lands and 57 underused lands.
\end{abstract}

Keywords: Urban Policy. City Statute. Social function of property. Geotechnology.

\section{INTRODUÇÃO}

O Parcelamento, Edificação ou Utilização Compulsórios (PEUC) é um instrumento jurídico e político previsto no artigo 182 da Constituição Federal de 1988 e regulamentado pela lei federal 10.257 de 2001, o Estatuto da Cidade (BRASIL, 2001; BRASIL, 1988). O instrumento foi instituído como forma de subsidiar a implementação da política urbana preconizada na carta magna (BRASIL, 2015; INSTITUTO POLIS, 2002).

O princípio que norteia o referido instrumento é o da 'função social da cidade e propriedade', cujo direito de propriedade é submetido aos interesses da coletividade e a ordem pública (BRASIL, 2001; BRASIL, 1988). Em linhas gerais, o PEUC visa intervir nos terrenos urbanos não edificados, subutilizados e não utilizados, de modo que estes cumpram com o pleno desenvolvimento das funções sociais da cidade e propriedade urbana, desse modo, subsidiando o ordenamento territorial no âmbito dos municípios (BRASIL, 2015; BRASIL, 1988). Cabe ao poder público municipal definir a área de incidência do PEUC no plano diretor 
e regulamentar os critérios para o seu exercício (BRASIL, 2015; INSTITUTO POLIS, 2002).

Considerando o exposto, o imóvel que estiver na área de incidência do PEUC e não cumprir com os índices de parcelamento e edificação do solo previstos em lei, estará sujeito ao parcelamento ou edificação compulsórios. Com isso, após ser notificado pelo poder público municipal, o imóvel deve ser parcelado ou utilizado, caso contrário pode sofrer as sanções previstas em lei (BRASIL, 2015; BRASIL, 2001).

O plano diretor do município de Florianópolis, instituído pela Lei Complementar n. 482/2014, prevê a aplicação do PEUC no artigo n. 254, especificando nos parágrafos 1, 2, 3, 4, 5 e 7 os critérios para a sua incidência. Contudo, as delimitações das áreas de aplicação do instrumento não constam nos mapas da referida lei. Esta é uma situação recorrente em grande parte dos municípios brasileiros, pois além das questões sociais e políticas relacionadas a sua aplicação, a falta de métodos para automatizar o processo de seleção dos terrenos dificulta o mapeamento e sua aplicação. Diante disso, o presente estudo tem como objetivo principal evidenciar o potencial de aplicação do instrumento, demonstrando os procedimentos que podem ser executados para o mapeamento dos imóveis passíveis de aplicação do PEUC.

\section{DA FUNÇÃO SOCIAL AO PEUC}

O Estatuto da Cidade, instituído pela Lei Federal n. 10.257 de 2001, regulamenta os dispositivos previstos na lei maior, prevendo diversos instrumentos para a execução da política urbana, entre eles, o PEUC (BRASIL, 2001). O Estatuto fortalece os dispositivos constitucionais e ressalta a necessidade da fixação de condições e prazos para o estabelecimento do PEUC. Ainda, é necessária a aprovação de uma lei específica municipal que defina os critérios para a aplicação do instrumento (BRASIL, 2001).

Uma importante contribuição trazida pelo Estatuto foi a definição dos prazos para que o proprietário cumpra com as exigências estabelecidas pelo poder público em parcelar, edificar ou utilizar o seu imóvel. No artigo $5^{\circ}$, parágrafo 4, a lei menciona o prazo de um ano após a emissão da notificação para que seja protocolado o projeto no órgão competente, e dois anos a partir da aprovação do projeto para iniciar as obras do empreendimento (BRASIL, 2001).

Caso não sejam cumpridos os prazos estabelecidos pelo poder público municipal, pode ser aplicada a majoração da alíquota do Imposto Predial e Territorial Urbano durante 5 anos, um outro instrumento previsto no Estatuto da Cidade denominado de IPTU Progressivo no Tempo, e posteriormente, a desapropriação mediante o pagamento de títulos (BRASIL, 2001). Estes instrumentos de política urbana são destinados a impedir e inibir o processo de especulação imobiliária no espaço urbano. Dessa forma, o poder público municipal fica juridicamente amparado para exigir o cumprimento da função social da propriedade urbana (INSTITUTO POLIS, 2002).

\section{O PLANO DIRETOR DO MUNICÍPIO DE FLORIANÓPOLIS}

O plano diretor de Florianópolis foi instituído pela lei complementar 482 de janeiro de 2014, prevendo o PEUC no capítulo 2, artigo 254 (FPOLIS, 2014). Os limites de uso e ocupação do solo estão expressos no anexo F01 da referida lei. Cada zona de uso e ocupação do solo possui um coeficiente de aproveitamento que é utilizado para calcular a área edificável permitida dos terrenos, tanto a área mínima quanto máxima.

O terreno subutilizado é definido no parágrafo 2, do artigo 254 como: "os terrenos onde, embora edificados, a cobertura vegetal e as características ambientais não são passíveis de preservação, e a soma das áreas construídas seja consideravelmente inferior ao permitido pelo mínimo da respectiva área" (FPOLIS, 2014). Desse modo, os terrenos são considerados subutilizados quando a área construída é inferior ao limite mínimo definido pelo plano diretor e não se encontram em área de preservação, ou seja, quando não atingem o mínimo de área construída para o cumprimento da função social e não possuem restrições ambientais.

Especificamente, a lei não define os critérios para os imóveis não edificados e não utilizados. Contudo, entende-se que o terreno não edificado é aquele cuja área construída é igual a zero, ou seja, o terreno baldio, enquanto que o imóvel não utilizado é o terreno sem ocupação: o terreno sem uso ou abandonado (BRASIL, 2015).

Conforme disposições do Art. 254 da lei 482 exclui-se do PEUC os terrenos cobertos por vegetação 
de interesse ambiental, áreas sem infraestruturas de abastecimento de água, esgotamento sanitário e distribuição de energia elétrica $\left(\S 1^{\circ}\right)$, áreas incluídas em reserva fundiária $\left(\S 3^{\circ}\right)$, áreas de preservação cultural $\left(\S 5^{\circ}\right)$ e os terrenos para fins de preservação arqueológica, arquitetônica, etnográfica, histórica ou paisagística e áreas verdes $\left(\S 7^{\circ}\right)$.

\section{CARACTERIZAÇÃo DA ÁREA DE ESTUDO}

A área de estudo situa-se na porção central do bairro Campeche em Florianópolis - SC, conforme o mapa da Figura 1. A definição da área deu-se pelo fato de que a expansão urbana horizontal no Bairro Campeche vem ocasionando o surgimento de diversos espaços ociosos, portanto, sendo áreas especuláveis e sujeitas ao PEUC. Além disso, a área de estudo pretende ser um piloto para demonstração do método proposto.

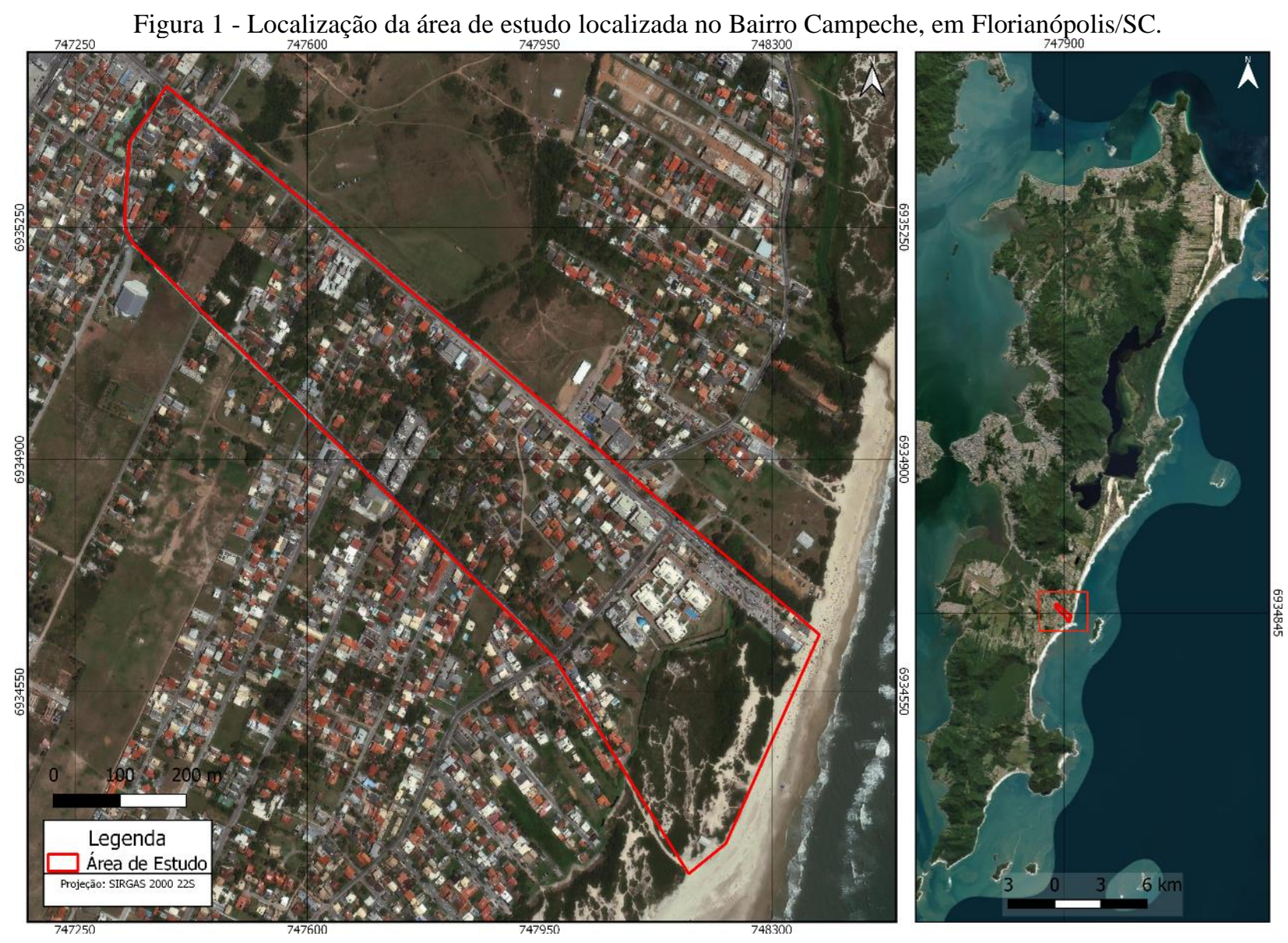

Fonte: Os autores (2020).

No Campeche, desde a ocupação no século XIX até meados do século XX, as relações de produção eram caracterizadas pelas práticas comunais e rurais. Contudo, no final do século XX a localidade passou por transformações, sobretudo devido ao processo de urbanização do município de Florianópolis e região, tornando-se uma das áreas mais populosas do município (RIZZO, 2013; PELUSO JR, 1991).

Em 1985 foi regulamentado o Plano Diretor dos Balneários, que expandiu o uso e ocupação do solo para as áreas interiores do município. Com isso, as áreas até então rurais, passaram a ser definidas para usos urbanos (MOREIRA, 2009), como foi o caso do bairro Campeche.

Em 1989, foi proposto pelo Instituto de Planejamento Urbano de Florianópolis - IPUF o Plano de Desenvolvimento da Planície Entremares, Campeche e Região (AMARANTE, 2016). O plano foi baseado na criação da 'Cidade Nova do Campeche' e a 'Tecnópolis do Campeche', ideias oriundas do modelo de urbanismo das cidades inglesas difundidas por Milton Keynes na década de 1960. A ideia dos planejadores era criar uma área autônoma e descentralizada, com uma população aproximada de 450.000 habitantes (AMARANTE, 2016; RIZZO, 2013), o que fez, em seu princípio, que a localidade viesse a se tornar em uma extensa área residencial. 
Segundo o Instituto Brasileiro de Geografia e Estatística - IBGE, a população do bairro era de 7.514 em 1991, passando para 18.570 em 2000, e atingindo 29.982 em 2010 (IBGE, 1991; 2003; 2011), o que demonstra um crescimento populacional acelerado nas últimas décadas. Atualmente, o uso e ocupação do solo são estabelecidos pela lei complementar 482 de 2014, o Plano Diretor de Urbanismo do Município de Florianópolis. A área de estudo compreende quatro macros áreas de usos urbanos estabelecidas pelo microzoneamento do plano diretor (Figura 2) e cada zona possui o seu próprio coeficiente de aproveitamento mínimo - CA (Quadro 1).

Quadro 1 - Limites de uso e ocupação por zona. Dados do Plano Diretor do município de Florianópolis.

\begin{tabular}{|c|c|c|}
\hline Código da zona & Nome da zona & CA Mínimo \\
\hline AMC-2.5 & Área Mista Comercial & 0.25 \\
\hline ARM-2.5 & Área Residencial Média & 0.20 \\
\hline ARP-2.5 & Área Residencial Predominante & 0.25 \\
\hline ATR-2.5 & Área Turística Residencial & \\
\hline
\end{tabular}

Fonte: Florianópolis (2014).

Figura 2 - Zoneamento da área de estudo obtido do Plano Diretor do município de Florianópolis.

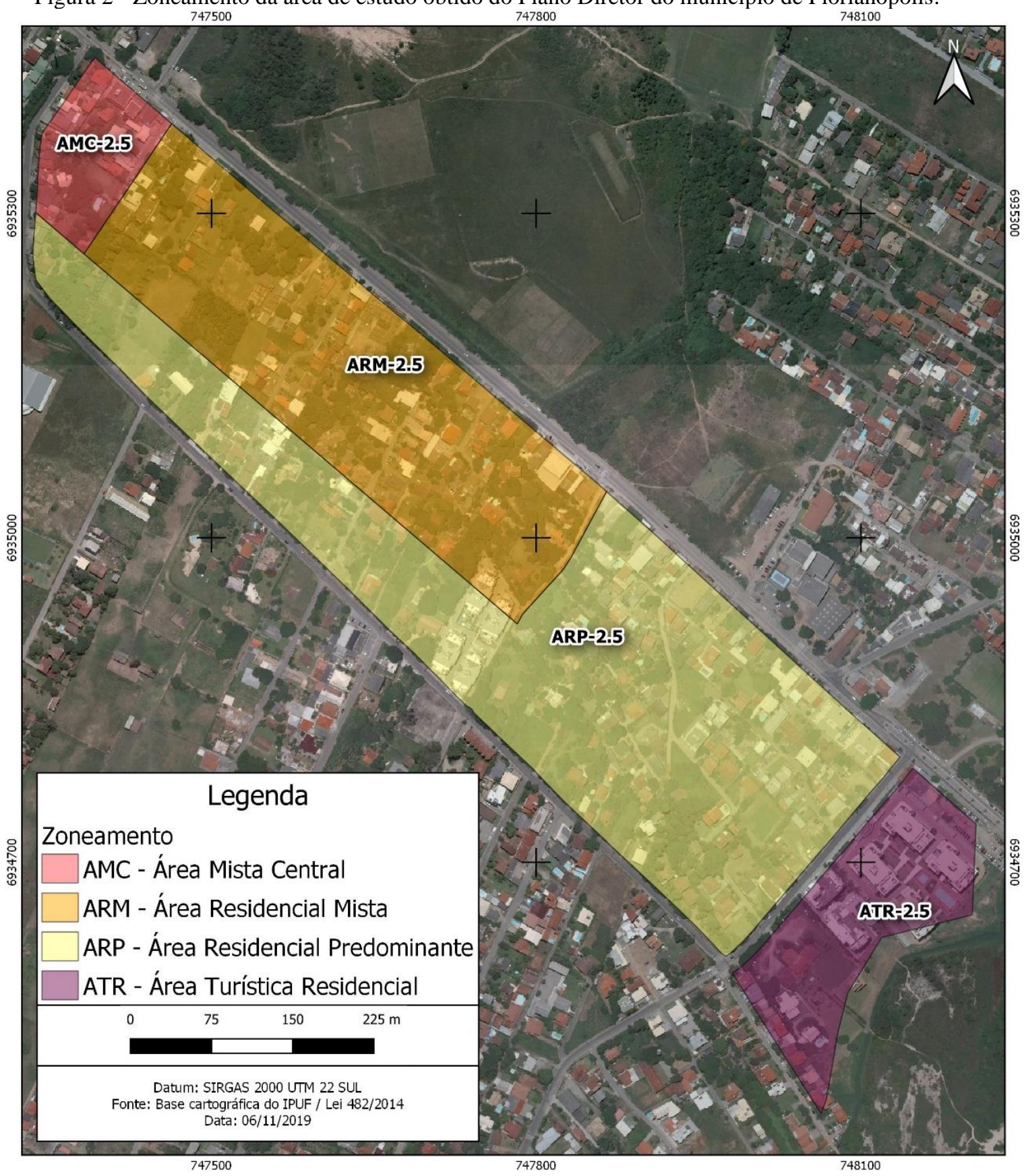

Fonte: Os autores (2020). 


\subsection{A base de dados da prefeitura municipal de Florianópolis}

A gestão da geoinformação oficial do município de Florianópolis é uma atribuição da Diretoria de Cadastro, Geoprocessamento e Pesquisa do Instituto de Pesquisa e Planejamento Urbano de Florianópolis IPUF. No que se refere a cartografia, até o ano de 1996 o Município dispunha de uma base cartográfica em escala 1:10.000, restituída de forma analógica a partir do levantamento aerofotogramétrico executado no triênio 1976/1977/1978 em escala 1:25.000. Esta foi a única base cartográfica disponível no município, e teve ampla utilização na elaboração de projetos de gestão e planejamento do território municipal. A partir de 1997, tendo em vista a desatualização da base produzida, o município iniciou um programa cartográfico digital na escala 1:2.000, e de 1997 a 2007 foram mapeados com restituição digital todos os distritos administrativos do município (TEIXEIRA; SILVA, 2018).

O Cadastro Territorial Urbano foi implantado no ano de 1982, desde então é sistematicamente atualizado. A atualização da base cartográfica cadastral é realizada por técnicos do IPUF, em maior parte por meio da vetorização digital de ortofotos, e em alguns casos usando levantamentos de campo. Em 2003, o Município desenvolveu seu primeiro projeto de geoprocessamento corporativo, tendo como foco principal a modernização do Cadastro Territorial Urbano, por intermédio da integração da base cartográfica com o banco de dados alfanumérico da Secretaria da Fazenda do município (TEIXEIRA; SILVA, 2018).

$\mathrm{O}$ aumento e a complexidade das demandas na gestão territorial municipal, junto a necessidade de acesso a dados geográficos por parte da sociedade e ao mesmo tempo a evolução tecnológica das últimas décadas, fizeram com que grande parte das rotinas administrativas da Prefeitura Municipal de Florianópolis se relacionassem com o sistema de geoprocessamento corporativo. A exemplo disso, as Consultas de Viabilidade de Construção, Consultas de Viabilidade de Instalação, Consultas Ambientais, dentre outras rotinas, estão relacionadas a inscrição imobiliária dos lotes registrados no Cadastro Territorial Urbano. Para atender esse alto número de demandas, periodicamente houve atualizações e melhorias na tecnologia do sistema e na base de dados do geoprocessamento corporativo desde sua implantação (TEIXEIRA, 2017).

Atualmente, o município de Florianópolis dispõe de um aerolevantamento do ano 2016, em escala 1:1.000, que é utilizado para atualização da base cartográfica municipal. O que se percebe é que pelo acelerado processo de urbanização dos últimos anos, algumas partes do município não tiveram sua cartografia cadastral atualizada. Uma dessas áreas é a do bairro Campeche, utilizado como área de estudo no presente trabalho. Foi possível constatar que a estrutura fundiária estava compatível com a camada vetorial de lotes, porém, o mesmo não foi observado com a camada vetorial de edificações, que apresentou maior grau de desatualização em relação a ortofoto.

\section{MATERIAIS E MÉTODOS}

O primeiro passo para a identificação dos imóveis sujeitos ao PEUC é a delimitação da área de incidência, onde os dados serão coletados para o mapeamento dos terrenos passíveis ao instrumento. O estudo foi realizado com o emprego dos dados da base cartográfica do município de Florianópolis, tendo como foco a área de estudo apresentada na Figura 1. Além disso, foram coletados dados mediante a fotointerpretação de imagens aéreas.

Os dados da base cartográfica municipal foram obtidos com o IPUF. Foram coletados os seguintes dados digitais no formato shapefile: estrutura fundiária (lotes) e plano diretor (zoneamento). Além disso, foram fornecidas as ortofotos digitais na escala de 1:1000 do ano de 2016.

Em seguida, foi realizada a coleta dos dados de edificações. Neste caso, os dados foram coletados mediante a fotointerpretação das ortofotos cedidas pelo IPUF, e posterior vetorização das feições com o uso do programa QGIS. Após a coleta de dados, foi necessária a estruturação das tabelas de dados dos arquivos vetoriais coletados, de modo a padronizar os campos necessários para o processamento dos terrenos sujeitos ao PEUC.

Com os dados estruturados, foram executadas as operações de geoprocessamento das informações mediante o uso do programa QGIS. Ao final, foram obtidos os terrenos subutilizados e não edificados da área de estudo. A Figura 3 mostra o fluxo dos processos adotados. 
Figura 3 - Etapas para a realização do estudo.

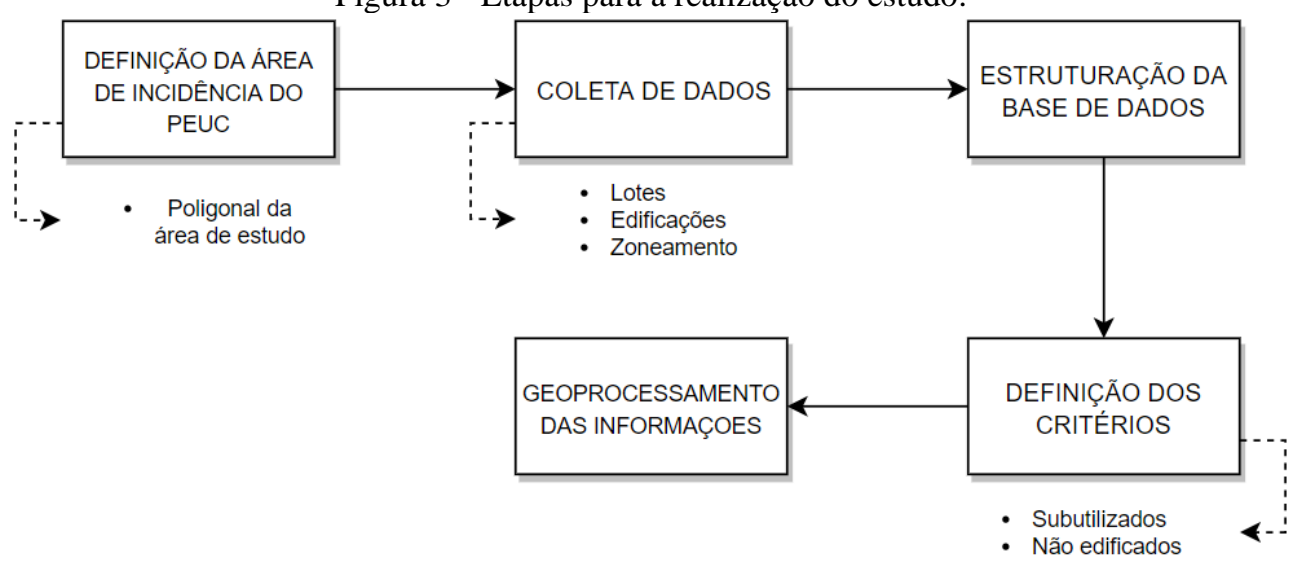

Fonte: Os autores (2020).

\subsection{Definição da área de incidência}

A área de incidência para estudo dos terrenos passíveis de aplicação do PEUC localiza-se na área central do bairro Campeche (Figura 1). A área foi escolhida como piloto para testes da metodologia. A delimitação da poligonal foi gerada a partir da vetorização no programa QGIS.

Na delimitação da área de incidência foram observadas as restrições dispostas nos parágrafos 1, 3, 5 e 7 do artigo 254, lei municipal 482 de 2014. Portanto, foram excluídos do estudo os terrenos situados em APP's - Áreas de Preservação Permanente.

\subsection{Coleta de dados}

Para a realização do estudo foram coletados os seguintes dados: estrutura fundiária (lotes), edificações, plano diretor (zoneamento) e imagens digitais (ortofotos), conforme demonstra o Quadro 2.

Quadro 2 - Bases de dados cartográficos. Dados coletados no IPUF e por vetorização.

\begin{tabular}{|c|c|c|}
\hline Base Cartográfica & Fonte & Data \\
\hline Imagens aéreas 1:1.000 & IPUF & 2016 \\
\hline Estrutura Fundiária & IPUF & 2015 \\
\hline Plano Diretor & IPUF & 2015 \\
\hline Edificações & Autores & 2016 \\
\hline
\end{tabular}

Fonte: Os autores (2020).

A estrutura fundiária consiste na representação dos polígonos das parcelas territoriais, e foi cedida em formato shapefile pelo IPUF, de um total de 242 lotes que conformaram a área de estudo.

As edificações foram fotointerpretadas nas imagens fornecidas pelo IPUF e vetorizadas com auxílio do programa QGIS. Com escala 1:1000, as imagens aéreas são resultado do aerolevantamento feito pelo município em 2016 e possuem boa resolução para fotointerpretação das feições geográficas. A identificação das edificações foi realizada com apoio do Google Street View, possibilitando a visualização da fachada dos imóveis, auxiliando o processo de fotointerpretação e conferindo melhores condições para representação dos polígonos. Além da vetorização dos polígonos das edificações, foi coletado o número de pavimentos das edificações. Ao final, foram vetorizados 400 polígonos de edificações, das quais 97 com 2 pavimentos.

O microzoneamento do plano diretor foi cedido no formato shapefile pelo IPUF, tendo como atributos o código e descrição de cada zona. O coeficiente de aproveitamento (CA) de cada zona foi levantado no anexo F02 da Lei Complementar municipal 482/2014 (FPOLIS, 2014).

A Figura 4 representa o mapa com os dados espaciais das edificações e lotes mapeados. 
Figura 4 - Dados vetoriais dos lotes e edificações. Os lotes da base cartográfica municipal e edificações obtidas por

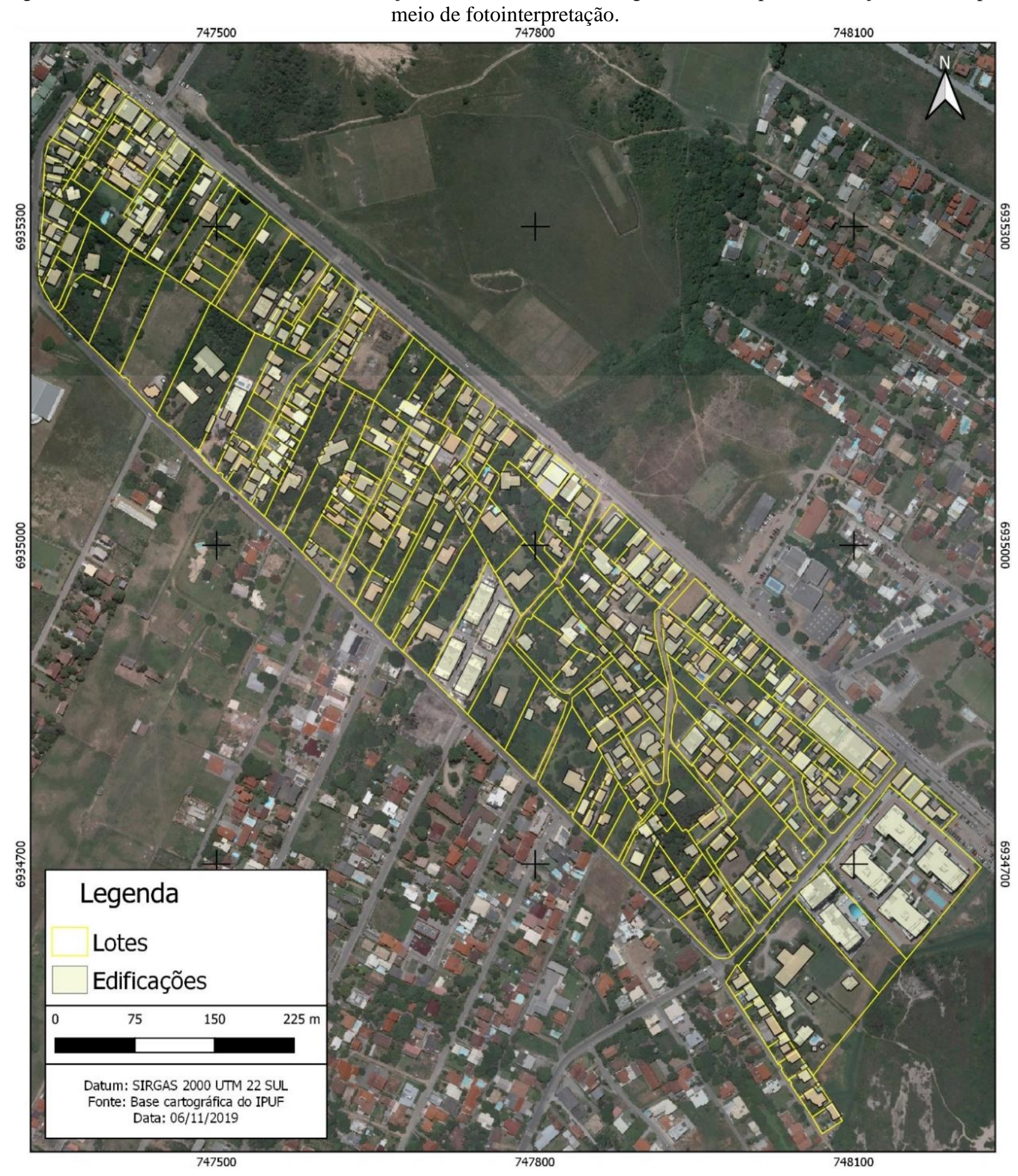

Fonte: Os autores (2020).

\subsection{Estruturação da base de dados}

A etapa de estruturação da base de dados consistiu na organização e estruturação da tabela de dados dos arquivos shapefiles, tendo como objetivo preparar os dados para o processamento no QGIS. A tabela dos lotes possui o identificador único das feições e o código do lote da base cadastral do município. Os campos restantes são nulos e serão processados pelos algoritmos de processamento do QGIS (Quadro 3). 
Quadro 3 - Descrição dos campos da tabela de lotes.

\begin{tabular}{|c|c|}
\hline Nome do Campo & Descrição \\
\hline id & Código sequencial do registro \\
\hline cd_lote & Código do lote \\
\hline area_lote & Área do lote $\left(\mathrm{m}^{2}\right)$ \\
\hline area_edif_fi & Área total edificada do lote $\left(\mathrm{m}^{2}\right)$ \\
\hline zon & Zona de uso e ocupação do lote \\
\hline ca_min & Coeficiente de aproveitamento mínimo do terreno \\
\hline min_fun_so & Área mínima edificável para o cumprimento da função social \\
\hline situacao & Situação do lote: subutilizado ou não edificado \\
\hline
\end{tabular}

Fonte: Os autores (2020).

A tabela de edificações possui o identificador único das feições, o número de pavimentos das edificações vetorizadas e outros campos nulos que serão processados com os algoritmos de processamento do QGIS. O Quadro 4 mostra a estrutura da tabela de edificações.

Quadro 4 - Descrição dos campos da tabela de edificações.

\begin{tabular}{|c|c|}
\hline Nome do Campo & Descrição do Campo \\
\hline id_edif & Código sequencial da geometria \\
\hline cd_lote & Código do lote \\
\hline area_edif & Área da geometria $\left(\mathrm{m}^{2}\right)$ \\
\hline num_pv & Número de pavimentos edificados do imóvel \\
\hline area_edif_fi & Área total edificada \\
\hline
\end{tabular}

Fonte: Os autores (2020).

Por fim, a tabela de zoneamento possui o identificador único das feições, o código do zoneamento e o coeficiente de aproveitamento mínimo da zona. O Quadro 5 mostra a estrutura da tabela do zoneamento.

Quadro 5 -Descrição dos campos da tabela do zoneamento.

\begin{tabular}{|c|c|}
\hline Nome do Campo & Descrição do Campo \\
\hline id_zon & Código sequencial da geometria \\
\hline cd_zon & Código do lote \\
\hline ca_min & Área da geometria $\left(\mathrm{m}^{2}\right)$ \\
\hline
\end{tabular}

Fonte: Os autores (2020).

\subsection{Definição dos critérios}

Para a realização do estudo foram adotados os seguintes critérios:

1 - Terrenos não edificados: aqueles cuja área construída é igual a zero, ou seja, os terrenos baldios.

2 - Terrenos subutilizados: aqueles em que a soma total da área edificada é inferior ao aproveitamento mínimo exigido em lei, ou seja, são os terrenos que possuem a área edificada menor do que o mínimo para o cumprimento da função social.

\subsection{Geoprocessamento}

A etapa de geoprocessamento consistiu no processamento dos dados e informações no QGIS. O Quadro 1 mostra todos os processamentos executados, bem como as ferramentas e camadas utilizadas. Já o Quadro 2 mostra os parâmetros que foram utilizados no processamento via QGIS.

O primeiro procedimento consistiu no cálculo da área construída das edificações que foram vetorizadas. Para tanto foi utilizado o algoritmo '\$area' na ferramenta da 'Calculadora de Campo' do QGIS, onde foi possível atualizar a área das geometrias vetorizadas utilizando o campo 'area_edif' da tabela de atributos da camada de edificações, conforme o id número 1 do Quadro 6 [Id 1]. Posteriormente foi calculado a área construída das edificações considerando o número de pavimentos. Para tanto, foi utilizado uma multiplicação entre os campos 'area_edif' e 'num_pv, novamente com auxílio da ferramenta da 'Calculadora de Campo'. Neste caso, o campo atualizado foi o 'area_edif_fi', que representa a área edificada com a soma da área dos pavimentos superiores [Id 2].

O próximo passo foi identificar o código do lote de cada edificação desenhada, ou seja, a localização de cada edificação dentro da malha de lotes do município. Para tanto, foram gerados os centroides da camada 
de edificação e se utilizou a ferramenta 'Vetor $>$ Geometrias $>$ Centroides...' [Id 3]. Com os centroides gerados, foi realizado uma união espacial dos atributos entre o ponto da edificação (centroide) e o polígono do lote, com isso o atributo do código do lote, 'cd_lote' da camada dos terrenos/lotes foi copiado para a tabela da camada dos centroides das edificações. O procedimento foi realizado com auxílio da ferramenta 'Unir atributos pela localização (sumário)' da caixa de ferramentas do QGIS, e com isso foi gerado um campo temporário na camada dos centroides com o código do lote chamado 'cd_lote_min' [Id 4]. Em seguida, foi atualizado o campo 'cd_lote' da camada dos centroides das edificações, utilizando como base o campo temporário 'cd_lote_min'. A atualização foi feita utilizando a 'Calculadora de Campo' do QIGS [Id 5].

O próximo passo foi calcular a área total construída das edificações constantes nos terrenos. Para tanto, foi utilizado o algoritmo 'Estatísticas por categoria' constante na caixa de ferramentas do QGIS, usando como camada de entrada a camadas dos centroides das edificações (que possui o código de cada lote - 'cd_lote'). Foi feito uma soma da área das edificações agrupando por 'cd_lote'. Ao final foi gerado uma tabela com o código do lote e a respectiva área das edificações somadas, ou seja, a área construída total de cada lote [Id 6].

O próximo passo foi necessário calcular a área do lote. Para a área do lote foi utilizado o algoritmo '\$area”, na calculadora de campo do QGIS, onde foi atualizado o campo 'área_lote' [Id 7]. Em seguida, foi necessário inserir a área total edificada de cada lote na camada de lotes a qual foi obtida a partir da camada dos centroides. Para tanto, foi utilizado a ferramenta 'Unir atributos pelo valor do campo' constante na caixa de ferramentas do QGIS, tendo como chave de união o valor do 'cd_lote'. Desse modo, foi possível copiar a área construída do ponto para a camada de lotes, onde foi gerado um campo temporário chamado 'sum' [Id 8]. Posteriormente, foi realizada a atualização do campo 'area_edif_fi' da camada de lotes e se usou a ferramenta da 'Calculadora de campo' para copiar o campo temporário, sum, para o campo 'area_edif_fi' [Id 9].

Em seguida, foi gerado o zoneamento, coeficiente de aproveitamento - CA e área mínima edificável de cada terreno. Para tanto, o primeiro passo foi gerar o zoneamento e CA de cada lote. Para tanto, foi utilizado a camada de zoneamento do plano diretor com o zoneamento e CA de cada zona. Foi utilizada a ferramenta 'Unir atributos pela localização (sumário)' da caixa de ferramentas do QGIS, no qual foram gerados campos temporários para 'nm_zon_min' e 'ca_min_2' [Id 10].

O próximo passo foi atualizar o zoneamento e CA de cada lote. Para atualizar o zoneamento foi utilizado a ferramenta da 'Calculadora de campo', atualizando o campo 'zon' a partir do campo temporário, que foi gerado na etapa nove, o campo 'nm_zon_min' [Id 11]. Com o CA foi realizado o mesmo procedimento, o campo temporário do 'ca_min_2' gerado na etapa 10 foi atualizado no campo 'ca_min' [Id 12].

Com a área do terreno gerada e seu respectivo CA, foi possível calcular a área mínima edificável do terreno. Para tanto, foi utilizado a ferramenta da 'Calculadora de campo' para atualizar o campo min_fun, a partir da fórmula de multiplicação da 'area_lote' x 'ca' [Id 13].

Com a área total edificada e a área mínima edificada de cada terreno foi possível calcular os terrenos subtulizados e não edificados. Para calcular os terrenos subutilizado foi utilizado a ferramenta da 'Calculadora de campo' do QGIS no qual atualizou-se o campo 'situacao' para '2', considerando se a área do terreno fosse menor do que a área construída [Id 14]. Em seguida, foi calculado os terrenos não utilizados, ou seja, aqueles com área construída igual a zero. Para tanto, foi utilizado a ferramenta da 'Calculadora de campo' do QGIS e atualizado o campo situação para ' 1 ' onde a área edificada estava igual a zero [Id 15].

Por fim, nos dois últimos procedimento foram excluídos os campos temporários constante na tabela de edificações e lotes. Foi utilizado a ferramenta 'Descartar campo(s)' constante na caixa de ferramentas do QGIS. 
Quadro 6 - Processos e ferramentas utilizadas para a obtenção dos imóveis não edificados e subutilizados.

\begin{tabular}{|c|c|c|c|c|c|c|}
\hline Id & Input & Processo & $\begin{array}{c}\text { Campo } \\
\text { Atualizado } \\
\end{array}$ & Ferramenta & Campos gerados & Output \\
\hline 1 & edificacao & $\begin{array}{c}\text { Calcular a área } \\
\text { construída das } \\
\text { vetorizações }\end{array}$ & area_edif & $\begin{array}{l}\text { Calculadora de } \\
\text { campo }\end{array}$ & - & edificacao \\
\hline 2 & edificacao & $\begin{array}{l}\text { Calcular a área } \\
\text { construída total } \\
\text { das edificações } \\
\text { (com número } \\
\text { de pavimentos) } \\
\end{array}$ & area_edif_fi & $\begin{array}{l}\text { Calculadora de } \\
\text { campo }\end{array}$ & - & edificacao \\
\hline 3 & $\begin{array}{l}\text { edificacao_cd_1 } \\
\text { ote }\end{array}$ & $\begin{array}{c}\text { Gerar } \\
\text { centroides das } \\
\text { edificações }\end{array}$ & - & Centroides & - & $\begin{array}{c}\text { edificacao_centroi } \\
\text { des }\end{array}$ \\
\hline 4 & $\begin{array}{l}\text { edificacao_cent } \\
\text { roides }\end{array}$ & $\begin{array}{l}\text { Gerar o código } \\
\text { do lote das } \\
\text { edificações por } \\
\text { união espacial } \\
\text { entre } \\
\text { edificações e } \\
\text { lotes } \\
\end{array}$ & - & $\begin{array}{l}\text { Unir atributos pela } \\
\text { posição (sumário) }\end{array}$ & cd_lote_min & edificacao_cd_lote \\
\hline 5 & $\begin{array}{l}\text { 706dificação_c } \\
\text { d_lote }\end{array}$ & $\begin{array}{c}\text { Atualizar o } \\
\text { código do lote } \\
\text { para o campo } \\
\text { cd_lote (usando } \\
\text { o cd_lote_min) }\end{array}$ & cd_lote & $\begin{array}{l}\text { Calculadora de } \\
\text { campo }\end{array}$ & - & edificacao_cd_lote \\
\hline 6 & $\begin{array}{l}\text { edificacao_cd_1 } \\
\text { ote }\end{array}$ & $\begin{array}{c}\text { Calcular a área } \\
\text { total construída } \\
\text { do terreno } \\
\end{array}$ & - & $\begin{array}{l}\text { Estatísticas por } \\
\text { categoria }\end{array}$ & sum & $\begin{array}{c}\text { edificacao_cd_lote } \\
\text { _sum }\end{array}$ \\
\hline 7 & lotes & $\begin{array}{c}\text { Calcular a área } \\
\text { do lote }\end{array}$ & area_lote & $\begin{array}{c}\text { Calculadora de } \\
\text { campo }\end{array}$ & - & lotes \\
\hline 8 & lotes & $\begin{array}{c}\text { Gerar a área } \\
\text { total edificada } \\
\text { do lote } \\
\end{array}$ & - & $\begin{array}{c}\text { Unir atributos pelo } \\
\text { valor de campo }\end{array}$ & sum & lotes_edifsum \\
\hline 9 & lotes_edifsum & $\begin{array}{l}\text { Atualizar a área } \\
\text { edificada do } \\
\text { total do lote } \\
\end{array}$ & area_edif_fi & $\begin{array}{l}\text { Calculadora de } \\
\text { campo }\end{array}$ & - & lotes_edifsum \\
\hline 10 & lotes_edifsum & $\begin{array}{c}\text { Gerar } \\
\text { zoneamento e } \\
\text { CA do lote }\end{array}$ & - & $\begin{array}{l}\text { Unir atributos pela } \\
\text { posição (sumário) }\end{array}$ & $\begin{array}{c}\text { nm_zon_min, } \\
\text { ca_min_2 }\end{array}$ & lotes_edifsum_zon \\
\hline 11 & $\begin{array}{l}\text { lotes_edifsum_ } \\
\text { zon }\end{array}$ & $\begin{array}{c}\text { Atualizar o } \\
\text { zoneamento do } \\
\text { lote } \\
\end{array}$ & zon & $\begin{array}{l}\text { Calculadora de } \\
\text { campo }\end{array}$ & - & lotes_edifsum_zon \\
\hline 12 & $\begin{array}{c}\text { lotes_edifsum_ } \\
\text { zon }\end{array}$ & $\begin{array}{l}\text { Atualizar o CA } \\
\text { mínimo do lote }\end{array}$ & ca_min & $\begin{array}{c}\text { Calculadora de } \\
\text { campo }\end{array}$ & - & lotes_edifsum_zon \\
\hline 13 & $\begin{array}{l}\text { lotes_edifsum_ } \\
\text { zon }\end{array}$ & $\begin{array}{l}\text { Calcular a área } \\
\text { mínima } \\
\text { edificável para } \\
\text { o cumprimento } \\
\text { da função social } \\
\end{array}$ & min_fun & $\begin{array}{l}\text { Calculadora de } \\
\text { campo }\end{array}$ & - & lotes_edifsum_zon \\
\hline 14 & $\begin{array}{c}\text { lotes_edifsum_ } \\
\text { zon }\end{array}$ & $\begin{array}{c}\text { Calcular os } \\
\text { terrenos } \\
\text { subutilizados } \\
\end{array}$ & situacao & $\begin{array}{l}\text { Calculadora de } \\
\text { campo }\end{array}$ & - & lotes_edifsum_zon \\
\hline 15 & $\begin{array}{l}\text { lotes_edifsum_ } \\
\text { zon }\end{array}$ & $\begin{array}{l}\text { Calcular os } \\
\text { terrenos não } \\
\text { edificados }\end{array}$ & situacao & $\begin{array}{l}\text { Calculadora de } \\
\text { campo }\end{array}$ & - & lotes_edifsum_zon \\
\hline 16 & $\begin{array}{l}\text { edificacao_cd_1 } \\
\text { ote_sum }\end{array}$ & $\begin{array}{c}\text { Descartar } \\
\text { campo } \\
\text { 'cd_lote_min' e } \\
\text { 'sum' ta tabela } \\
\text { de edificação } \\
\end{array}$ & - & $\begin{array}{l}\text { Descartar } \\
\text { campo(s) }\end{array}$ & - & edificacao_final \\
\hline 17 & $\begin{array}{c}\text { lotes_edifsum_ } \\
\text { zon }\end{array}$ & $\begin{array}{c}\text { Descartar } \\
\text { 'sum', } \\
\text { 'nm_zon_min', } \\
\text { 'ca_min_2' }\end{array}$ & - & $\begin{array}{l}\text { Descartar } \\
\text { campo(s) }\end{array}$ & - & lotes_final \\
\hline
\end{tabular}


Quadro 7 - Parâmetros utilizados para a geração dos terrenos não edificados e subutilizados.

\begin{tabular}{|c|c|}
\hline Procedimento & Parâmetros \\
\hline 1 & $\begin{array}{l}\text { - Atualiza campo existente }=\text { area_edif } \\
\text { - Expressão }=\text { \$area }\end{array}$ \\
\hline 2 & $\begin{array}{l}\text { - Atualiza campo existente }=\text { area_edif_fi } \\
\text { - Expressão }=\text { area_edif } * \text { num_pv }\end{array}$ \\
\hline 3 & $\begin{array}{c}\text { - Camada de entrada }=\text { edificacao } \\
\text { - Centroides }=\text { edificacao_centroides }\end{array}$ \\
\hline 4 & $\begin{array}{l}\text { - Camada de entrada }=\text { edificacao_centroides } \\
\text { - Unir camadas }=\text { lotes } \\
\text { - Predicado geométrico }=\text { intersecta, dentro } \\
\text { - Fields to summarise }=\text { cd_lote } \\
\text { - Summaries to calculate }=\text { min }\end{array}$ \\
\hline 5 & $\begin{array}{l}\text { - Atualiza um campo existente = cd_lote } \\
\text { - Expressão }=\text { cd_lote_min }\end{array}$ \\
\hline 6 & \\
\hline 7 & $\begin{array}{l}\text { - Camada de entrada }=\text { edificacao_cd_lote } \\
\text { - Field to calculate statistics }=\text { area_edif_fi } \\
\text { - Campo com categoria }=\text { cod_lote }\end{array}$ \\
\hline 8 & $\begin{array}{l}\text { - Atualiza campo existente = area_lote } \\
\text { - Expressão = \$area }\end{array}$ \\
\hline 9 & $\begin{array}{c}\text { - Camada de entrada }=\text { lotes } \\
\text { - Campo da tabela }=\text { cd_lote } \\
\text { - Camada de entrada } 2=\text { edificacao_cd_lote_sum } \\
\text { - campo da tablea } 2=\text { sum } \\
\text { - Camada } 2 \text { campos para cópia }=\text { sum }\end{array}$ \\
\hline 10 & $\begin{array}{l}\text { - Atualiza um campo existente = area_edif_fi } \\
\text { - Expressão: sum }\end{array}$ \\
\hline 11 & $\begin{array}{l}\text { - Camada de entrada }=\text { lotes_edifsum } \\
\text { - Unir camadas }=\text { zoneamento } \\
\text { - Predicado geométrico }=\text { intersecta, dentro } \\
\text { - Fields to summarise }=\text { cd_zon, ca } \\
\text { - Summaries to calculate }=\text { min }\end{array}$ \\
\hline 12 & $\begin{array}{l}\text { - Atualiza um campo existente }=\text { zon } \\
\text { - Expressão==: } \text { nm_zon_min }\end{array}$ \\
\hline 13 & $\begin{array}{l}\text { - Atualiza um campo existente }=\text { ca_min } \\
\text { - Expressão }=\text { ca_min2 }\end{array}$ \\
\hline 14 & $\begin{array}{l}\text { - Atualiza um campo existente }=\text { min_fun } \\
\text { - Expressão }=\text { area_lote } * \text { min_fun }\end{array}$ \\
\hline 15 & $\begin{array}{l}\text { - Atualiza um campo existente = situacao }- \text { Expressão = case } \\
\text { when "area_edif_fi" > "min_fun_so" then } 2 \text { else "situacao" end }\end{array}$ \\
\hline 16 & $\begin{array}{c}\text { - Atualiza um campo existente }=\text { situacao } \\
\text { - Expressão }=\text { case when "area_edif_fi" }=\text { '0' then } 1 \text { else } \\
\text { "situacao" end }\end{array}$ \\
\hline 17 & $\begin{array}{l}\text { - Camada de entrada }=\text { edificacao_cd_lote_sum } \\
\text { - Campos a serem descartados }=\text { cd_lote_min, sum }\end{array}$ \\
\hline 18 & $\begin{array}{l}\text { - Camada d entrada = camada unida } \\
\text { - Campos a serem descartaods }=\text { cd_lote_mi }\end{array}$ \\
\hline
\end{tabular}

Fonte: Os autores (2020).

\section{RESULTADOS E DISCUSSÕES}

\subsection{Grau de desatualização da base cartográfica cadastral da prefeitura}

A atualização da base cartográfica cadastral do Município de Florianópolis é realizada diariamente pelos técnicos do IPUF. Com foco na representação gráfica das parcelas territoriais, a camada vetorial dos lotes é atualizada conforme a aprovação de projetos de parcelamentos de solo ou levantamentos em campo, realizada pela comissão municipal do Projeto de Atualização Cadastral - PAC (TEIXEIRA, 2017).

Procedimento também realizado para os logradouros do município, conforme implantação de novas vias ou oficialização das existentes pelo legislativo municipal. Porém, para elaboração do presente trabalho optouse pela elaboração da camada vetorial de edificações, por intermédio da fotointerpretação e vetorização dos polígonos a partir da ortofoto do ano de 2016. Isso se deve por conta da necessidade de dados com validade espacial e temporal para aplicação da metodologia proposta neste trabalho. 


\subsection{Terrenos não edificados}

A classe dos imóveis não edificados engloba todos os terrenos cuja área total construída é igual a zero, ou seja, os terrenos baldios. O diagnóstico dos terrenos baldios normalmente é obtido mediante a pesquisa na base de dados cadastral da prefeitura, buscando os imóveis com área construída igual a zero. Para isso, é fundamental que a base cartográfica e alfanumérica do município esteja atualizada.

No âmbito deste estudo, os terrenos baldios foram identificados na etapa de vetorização das edificações, pois os terrenos que não apresentaram edificações digitalizadas ficaram com área edificada igual a zero. Desta forma, foram classificados como baldios. Ao final, foram identificados 21 terrenos com a área construída igual a zero, como demonstra o mapa dos terrenos não edificados expresso na Figura 5.

Além do trabalho de gabinete pode ser realizado o trabalho de campo, de modo a validar as informações obtidas, se os terrenos baldios efetivamente estão sem uso. Além disso, torna-se fundamental que os dados de outras bases possam subsidiar a exclusão dos possíveis terrenos sujeitos ao PEUC como, por exemplo, as informações da secretaria de obras referentes aos terrenos embargados na justiça ou àqueles que possuem construção em andamento ou mesmo as informações da secretaria de meio ambiente sobre as áreas ambientais, bem como a integração com outros setores da prefeitura que possam fornecer informações ao cadastro.

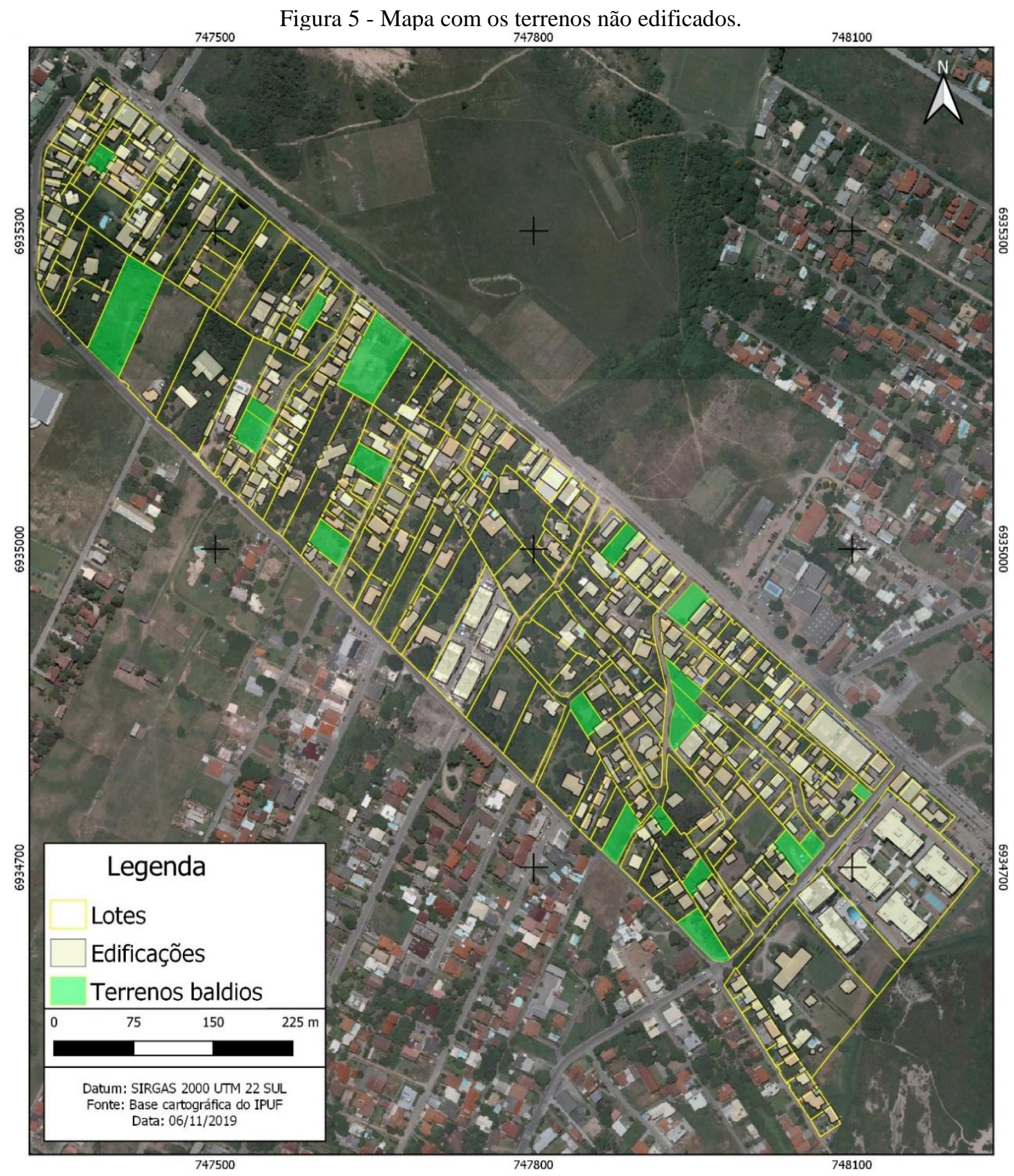

Fonte: Os autores (2020). 


\subsection{Terrenos subutilizados}

A classe dos terrenos subutilizados engloba os terrenos cuja área edificada é menor do que o limite mínimo exigido pela lei municipal. O limite mínimo para ser considerado um terreno subutilizado varia conforme a zona de uso e ocupação do solo ao qual o terreno se encontra, sendo calculada pela multiplicação da área do terreno e o coeficiente de aproveitamento da zona ao qual se encontra.

No âmbito deste estudo, a identificação dos terrenos subutilizados foi realizada após a identificação das seguintes variáveis dos terrenos: área mínima edificável e área total edificada.

A área mínima edificável para que o terreno cumpra a sua função social varia conforme a área do terreno e seu índice de aproveitamento. Desse modo, o cálculo da área mínima edificável é feito pela multiplicação a área do terreno e seu coeficiente de aproveitamento. Já a área total construída do terreno consiste na soma de todas as áreas de construções existentes no terreno, incluindo a área construída de todos os pavimentos. O QGIS permite calcular a área construída das feições desenhadas e obteve-se a área total das vetorizações dos polígonos das edificações. Identificada a área mínima edificável do terreno para o cumprimento da função social e a sua respectiva área total construída, é possível identificar quais os terrenos estão subutilizados, ou seja, com a área total construída menor do que o mínimo exigido em lei.

Empregando o método proposto, foram encontrados 57 terrenos que estavam na situação de subutilizados, com base na legislação municipal (Figura 6). Considera-se que é fundamental a elaboração de estudos temporais para apoiar a identificação dos terrenos subutilizados, pois as alterações urbanísticas podem mudar substancialmente a quantidade de terrenos sujeitos ao PEUC. Por exemplo, a legislação anterior poderia prever maior ou menor índice de edificação no terreno, o que deve ser considerado na análise de terrenos construídos em data anterior a legislação atual. Na situação anteriormente comentada, indica-se o filtro no cadastro pelo ano de construção dos imóveis, ou seja, pode-se ajustar um parâmetro de corte para que somente os lotes construídos em determinado intervalo de tempo sejam computados. 


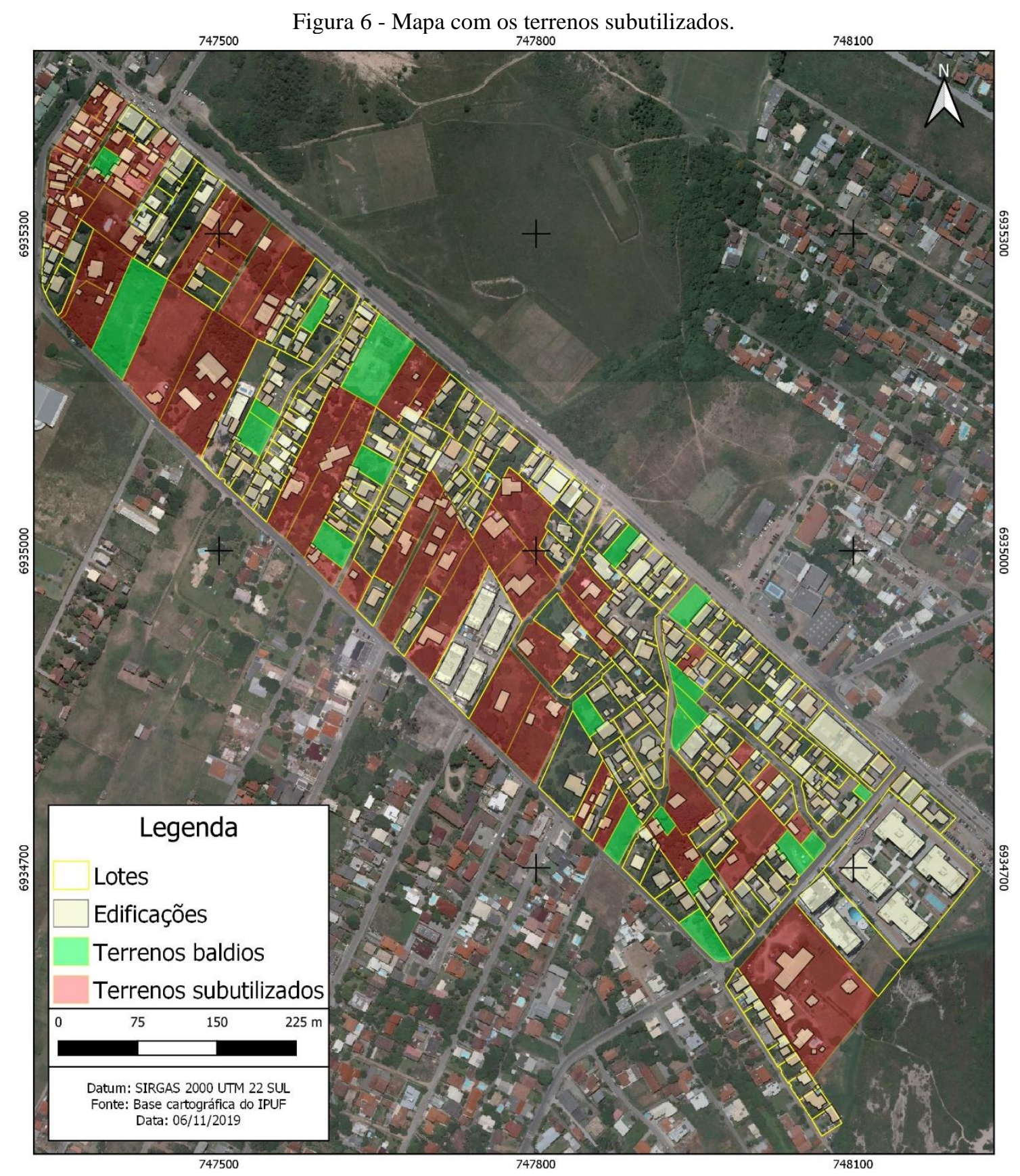

Fonte: Os autores (2020).

\section{CONSIDERAÇÕES FINAIS}

O método empregado possibilitou identificar de forma rápida e sistemática os terrenos não edificados e subutilizados de uma porção do território urbano, demonstrando-se viável a sua aplicação em outras regiões do território municipal. Para assegurar resultados que melhor representem a realidade, é indispensável a utilização de uma base cadastral com geometrias e atributos atualizados. Outro ponto importante é a identificação dos imóveis que estarão imunes à aplicação do instrumento.

O uso de geotecnologias gratuitas e livres é fundamental para apoiar a modernização das ações da administração pública, sobretudo na otimização de recursos com o uso de programas livres. Destaca-se a interoperabilidade do programa QGIS empregado neste estudo, deixando clara a possibilidade de incorporação do mesmo na rotina das administrações municipais. A metodologia de vetorização das feições mostrou-se adequada, pois a qualidade e atualidade da imagem contribuíram para uma maior precisão na fotointerpretação das feições geográficas (vetorização da área edificada dos imóveis).

Por fim, pode-se afirmar que a aplicação do instrumento PEUC é factível e dá aos municípios a possibilidade de induzir um uso e ocupação do solo mais adensado, adequado frente ao déficit habitacional presente nos municípios brasileiros. E, ao mesmo tempo, combater a retenção especulativa dos imóveis, 
tornando se uma política de solo importante para exercer a gestão territorial municipal.

\section{Contribuição dos Autores}

O autor Tiago Umberto Pazolini contribuiu na conceptualização, análise formal, investigação metodologia, software, validação e redação. O autor Everton da Silva contribuiu na supervisão, metodologia e redação final. O autor Kaliu Teixeira contribuiu na investigação, recursos, metodologia, análise formal, e redação.

\section{Conflitos de Interesse}

Os autores declaram que não há conflito de interesse.

\section{Referências}

AMARANTE, C. A Cidade Nova do Campeche: uma perspectiva histórica dos projetos de futuro para Florianópolis a partir das memórias dos moradores do Bairro. In: Encontro Nacional de História Oral. História Oral, Práticas Educacionais e Interdisciplinaridade. XIII, Porto Alegre, 2016. Anais... Porto Alegre, Associação Brasileira de História Oral. Universidade Federal do Rio Grande do Sul. UFRGS, 2016.

Disponível em: http://www.historiaoral.org.br/resources/anais/13/1462058347_ARQUIVO_artigoencontrohstoralpoa.pd f Acesso em: 18 out. 2020.

BRASIL. Constituição da República Federativa do Brasil. Brasília, Diário Oficial da União, 05 de outubro de 1988.

BRASIL, Lei Federal no 10.257 de 10 de julho de 2001. Regulamenta os arts. 182 e 183 da Constituição Federal, estabelece diretrizes gerais da política urbana e dá outras providências. Brasília, Diário Oficial da União, 11 de julho de 2001.

BRASIL, Parcelamento, Edificação ou Utilização Compulsórios (PEUC) e IPTU Progressivo no Tempo. Programa Nacional de Capacitação das Cidades. Coleção Cadernos técnicos de regulamentação e implementação de instrumentos do Estatuto da Cidade. Volume 2. 2015, 80p.

FLORIANÓPOLIS, Lei complementar $n^{\circ} 482$, de 17 de janeiro de 2014. Institui o plano diretor de urbanismo do município de Florianópolis. Diário Oficial do Município, 14 de janeiro de 2014.

INSTITUTO BRASILEIRO DE GEOGRAFIA E ESTATÍSTICA (IBGE). Base de Informação do Censo Demográfico 2010: Resultado do Universo por Setor Censitário. Rio de Janeiro, 2011.

INSTITUTO BRASILEIRO DE GEOGRAFIA E ESTATÍSTICA (IBGE). Censo demográfico 2000. Agregado por Setores Censitários dos Resultados do Universo - $2^{\text {a }}$ ed. Rio de Janeiro, 2003.

INSTITUTO BRASILEIRO DE GEOGRAFIA E ESTATÍSTICA (IBGE). Censo demográfico 1991. Rio de Janeiro, 1991.

INSTITUTO POLIS. Estatuto da Cidade: guia para implementação pelos municípios e cidadãos. $2^{\mathrm{a}}$ ed. Brasília, 2002. Disponível em: https://polis.org.br/publicacoes/estatuto-da-cidade-guia-paraimplementacao-pelos-municipios-e-cidadaos/ Acesso em: 18 out. 2020.

MOREIRA, A. S. O Processo Participativo no Plano Diretor - estudo de caso: Campeche/Florianópolis, SC - Brasil. Dissertação de mestrado. Universidade Estadual de Santa Catarina, Curso de Mestrado Profissional em Planejamento Territorial e Desenvolvimento Socioambiental. Florianópolis, 2009. Disponível em: http://www.tede.udesc.br/handle/tede/2012 Acesso em: 18 out. 2020.

MOURA, A. C. M; FREIRE, G. J. M. O papel do Cadastro Territorial Multifinalitário nas políticas públicas de planejamento e gestão urbana como apoio a instrumentos do Estatuto da Cidade. Revista Brasileira de Cartografia, vol. 65, $\mathrm{n} \quad 2, \quad 2013 \quad$ pp.315-325. Disponível em: http://www.seer.ufu.br/index.php/revistabrasileiracartografia/article/view/43839/23103 Acesso em: 18 
out. 2020 .

PELUSO JR, V. A. O crescimento populacional de Florianópolis e suas repercussões no plano e na estrutura da cidade. Estudos de Geografia Urbana de Santa Catarina. Florianópolis: Ed. Da UFSC: 1991. 400p.

RIZZO, P. M. B. O planejamento urbano no contexto da globalização: caso do plano diretor do Campeche em Florianópolis. Tese de doutorado. Universidade Federal de Santa Catarina, Programa de PósGraduação em Geografia, Florianópolis, 2013. 331p. Disponível em: http://eds.b.ebscohost.com/eds/detail/detail?vid=0\&sid=8c440a03-43fd-40fe-96b5aa1060ce3ea0\%40pdc-vsessmgr04\&bdata=Jmxhbmc9cHQtYnImc210ZT11ZHMtbGl2ZSZzY29wZT1zaXRl\#AN=uls.317524\&d $\mathrm{b}=\mathrm{cat} 07205 \mathrm{a}$ Acesso em: 18 out. 2020.

TEIXEIRA, K. O geoprocessamento na gestão territorial do município de Florianópolis. TCC (graduação) - Universidade Federal de Santa Catarina. Centro de Filosofia e Ciências Humanas. Geografia. 2017. Disponível em: http://search.ebscohost.com/login.aspx?direct=true\&db=ir01452a\&AN=riufsc.123456789.182339\&lang =pt-br\&site=eds-live $\&$ scope $=$ site Acesso em: 18 out. 2020.

TEIXEIRA, K; SILVA, E. O geoprocessamento na gestão territorial do município de Florianópolis. In: Congresso Brasileiro de Cadastro Técnico Multifinalitário e Gestão Territorial - COBRAC, 13, 2018, Florianópolis. Anais... $\quad$ Florianópolis, 2018. Disponível em: http://ocs.cobrac.ufsc.br/index.php/cobrac/cobrac2018/paper/download/580/226 Acesso em: 18 out. 2020.

\section{Biografia do autor principal}

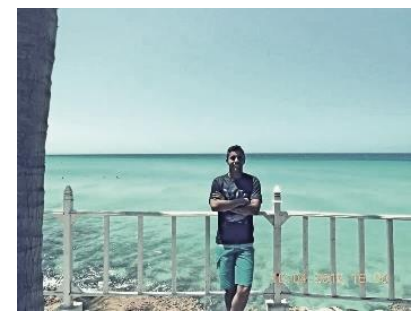

Tiago Umberto Pazolini, nascido na cidade de Curitibanos, Santa Catarina. É Técnico em Meio Ambiente pelo Instituto Federal de Santa Catarina - IFSC, Geógrafo pela Universidade Federal de Santa Catarina - UFSC e Mestre em Gestão Territorial pelo Programa de Pós-Graduação em Engenharia de Transportes e Gestão Territorial - PPGTG/ECV/UFSC. É especialista em geoprocessamento e Sistemas de Informação Geográfica - SIG. Possui experiência em projetos de Cadastro Territorial Multifinalitário e estudos ambientais. 